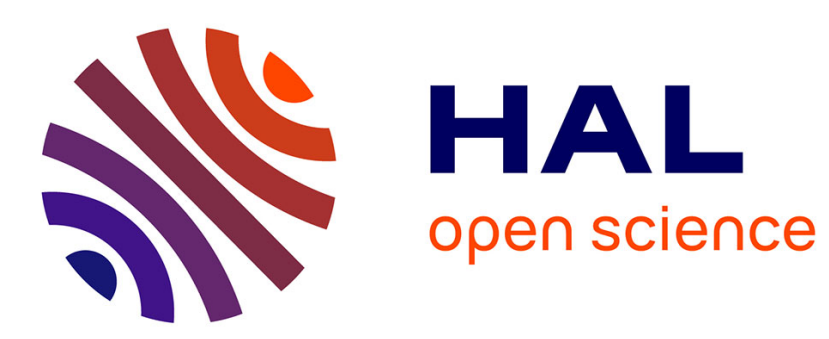

\title{
A novel Sensorless Control Strategy Based on Sliding Mode Observer for Non-Sinusoidal Seven-phase PMSM
}

\author{
Youssouf Mini, Ngacky Nguyen, Eric Semail
}

\section{To cite this version:}

Youssouf Mini, Ngacky Nguyen, Eric Semail. A novel Sensorless Control Strategy Based on Sliding Mode Observer for Non-Sinusoidal Seven-phase PMSM. The 10th International Conference on Power Electronics, Machines and Drives, Dec 2020, Nottingham, United Kingdom. pp.1-6. hal-02548169

\section{HAL Id: hal-02548169 \\ https://hal.science/hal-02548169}

Submitted on 20 Apr 2020

HAL is a multi-disciplinary open access archive for the deposit and dissemination of scientific research documents, whether they are published or not. The documents may come from teaching and research institutions in France or abroad, or from public or private research centers.
L'archive ouverte pluridisciplinaire HAL, est destinée au dépôt et à la diffusion de documents scientifiques de niveau recherche, publiés ou non, émanant des établissements d'enseignement et de recherche français ou étrangers, des laboratoires publics ou privés. 


\title{
A novel Sensorless Control Strategy Based on Sliding Mode Observer for Non-Sinusoidal Seven-phase PMSM Youssouf Mini ${ }^{1}$, Ngac Ky Nguyen ${ }^{1}$, Eric Semail ${ }^{1}$
}

\author{
${ }^{1}$ Arts et Metiers Institute of Technology, Univ. Lille, Centrale Lille, HEI, HESAM Université, ULR 2697 \\ L2EP - Laboratoire d'Electrotechnique et d'Electronique de Puissance, F-59000 Lille, France \\ Email : \{youssouf.mini; ngacky.nguyen; eric.semail\}@ensam.eu
}

\begin{abstract}
Keywords: Back-EMF observer, electrical integrated drives, seven-phase Permanent Magnet Synchronous Machine (PMSM), sensorless control, Sliding Mode Observer (SMO).
\end{abstract}

\begin{abstract}
This paper proposes a new sensorless control strategy based on a Sliding Mode Observer (SMO) for a non-sinusoidal sevenphase PMSMs. This strategy, based on all harmonics contained in the back-EMF, is compared to the classical sensorless control strategy using only the fundamental of back-EMF signal. As the novel sensorless control strategy estimate the rotor position by using different harmonics, it can lead to a good torque response compared to the classical strategy, specially in transient states. Therefore, in order to define the appropriate sensorless control strategy for the non-sinusoidal seven-phase PMSM, each sensorless control strategy will be highlighted in terms of robustness to the speed variation and torque ripple. Simulation results will be shown to verify the feasibility of the proposed methods.
\end{abstract}

\section{Introduction}

Multiphase machines have been used in integrated motor drives with the power inverter inside the machine [1]. They present some advantages compared to conventional threephase machines, such as reliability (operating under the loss of one or more phases) and compactness (reducing the total volume and weight of the integrated motor without electromagnetic compatibility phenomena) [1]. In this context, the replacement of the position encoder mounted at the end of the rotor shaft by a "soft" position sensor using only electrical sensors (current) or integrated magnetic sensors (Hall effect sensors) appears relevant. For that, an accurate sensorless control algorithm to substitute the encoder, essential for the vector control, can improve significantly the reliability and the compactness of integrated drives.

In the literature we can find several methods which propose the sensorless control of permanent magnet synchronous machines (PMSM) [2]. These methods are based mostly on the observers, such as Model Reference Adaptive System (MRAS) [3], Extended Kalman Filter (EKF) [4], Luenberger Observer (LO) [5] and Sliding Mode Observer (SMO) [6]. Among these methods, SMO will be chosen to achieve the sensorless control of the seven-phase PMSM due to its simple implementation compared to EKF, which requires an important computation time especially in the case of multiphase machines. Furthermore, in terms of robustness, the SMO presents a robust structure against the variations of machine parameters and noise compared to the MRAS and LO [6].

The main contribution of this paper is to compare two sensorless control strategies for three diferent non-sinusoidal seven-phase PMSM. The first strategy, based only on the fundamental of the back-EMF (main fictitious machine signals), is developed in some papers [6]-[7]. The second strategy, which is totally original, uses the harmonics contained in the back-EMF signal in order to estimate the rotor position. These two sensorless control strategies will be tested on three differents seven-phase PMSMs, in ordrer to identify the robust and efficient strategy against the speed variation and torque ripple.

\section{Seven-phase PMSM modelling}

The machine model in the natural frame, assuming no magnetic saturation and no saliency, can be described by [8]:

$$
\vec{v}=R \vec{i}+[\mathbf{L}] \frac{d \vec{i}}{d t}+\vec{e}
$$

Where $\vec{v}$ is the 7-dimension stator voltage vector, $\vec{i}$ is the 7 dimension stator current vector and $\vec{e}$ is the 7-dimension of the back-EMF vector. $R$ and $\mathbf{L}$ are respectively the stator resistance and the stator inductance matrix.

Applying the Concordia matrix [8], the seven-phase PMSM can be decomposed to several fictitious machines. The real seven-phase PMSM is equivalent to 3 fictitious two-phase machines associated to the different harmonics as shown in Fig. 1. The homopolar fictitious machine is not considered with a wye connection [8].

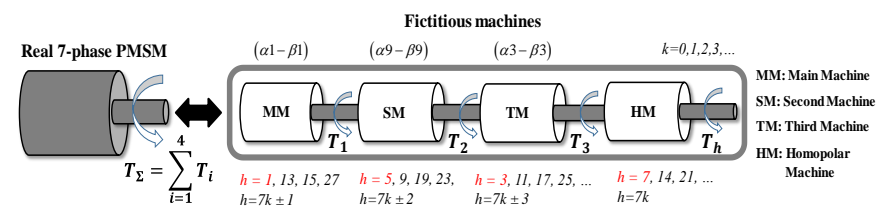

Fig. 1 Fictitious machines and associated harmonics of seven-phase PMSM [8] (even harmonics are negliged)

The model of the 7-phase PMSM in the stationary reference frame $(\alpha-\beta)$, considering the $1^{\text {st }}$ harmonic in the Main 
Machine (MM), the $9^{\text {th }}$ harmonic in the Secondary Machine (SM) and the $3^{\text {rd }}$ harmonic in Tertiary Machine (TM), is given by following equations:

$$
\left\{\begin{array}{l}
L_{p} \frac{d \vec{i}_{\alpha \beta 1}}{d t}=-R \vec{i}_{\alpha \beta 1}-\vec{e}_{\alpha \beta 1}+\vec{v}_{\alpha \beta 1} \\
L_{s} \frac{d \vec{i}_{\alpha \beta 9}}{d t}=-R \vec{i}_{\alpha \beta 9}-\vec{e}_{\alpha \beta 9}+\vec{v}_{\alpha \beta 9} \\
L_{t} \frac{d \vec{i}_{\alpha \beta 3}}{d t}=-R \vec{i}_{\alpha \beta 3}-\vec{e}_{\alpha \beta 3}+\vec{v}_{\alpha \beta 3}
\end{array}\right.
$$

$\vec{i}_{\alpha \beta 1}=\left[\begin{array}{ll}i_{\alpha 1} & i_{\beta 1}\end{array}\right]^{T}, \quad \vec{i}_{\alpha \beta 9}=\left[\begin{array}{ll}i_{\alpha 9} & i_{\beta 9}\end{array}\right]^{T}$ and $\quad \vec{i}_{\alpha \beta 3}=\left[\begin{array}{ll}i_{\alpha 3} & i_{\beta 3}\end{array}\right]^{T}$ represent respectively the currents of the MM, SM and TM. Where $L_{p}, L_{s}$ and $L_{t}$ represent respectively the inductance of the MM, SM and the TM.

As the fictitious machines are mechanically coupled, the electromagnetic torque of the 7-phase PMSM can be obtained by the sum of torques provided by each fictitious machine. Therefore, the torque is equal to:

$$
\Gamma=\Gamma_{1}+\Gamma_{9}+\Gamma_{3}
$$

where: torque of the MM $\Gamma_{1}=\frac{\left[\begin{array}{ll}e_{\alpha 1} & e_{\beta 1}\end{array}\right]\left[\begin{array}{ll}i_{\alpha 1} & i_{\beta 1}\end{array}\right]^{T}}{\Omega}$, torque of the SM $\Gamma_{9}=\frac{\left[\begin{array}{ll}e_{\alpha 9} & e_{\beta 9}\end{array}\right]\left[\begin{array}{ll}i_{\alpha 9} & i_{\beta 9}\end{array}\right]^{T}}{\Omega}$ and torque of the TM $\Gamma_{3}=\frac{\left[\begin{array}{ll}e_{\alpha 3} & e_{\beta 3}\end{array}\right]\left[\begin{array}{ll}i_{\alpha 3} & i_{\beta 3}\end{array}\right]^{T}}{\Omega}$, with $\Omega$ the mechanical speed.

The back-EMF in stationary reference frame $(\alpha-\beta)$ of each fictitious machine is expressed as (only the $1^{\text {st }}, 9^{\text {th }}$ and $3^{\text {rd }}$ harmonics are considered):

$$
\left\{\begin{array}{l}
e_{\alpha \beta 1}=-\psi_{1} \omega_{r}(\sin \theta-j \cos \theta) \\
e_{\alpha \beta 9}=-\psi_{9} \omega_{r}(\sin 9 \theta-j \cos 9 \theta) \\
e_{\alpha \beta 3}=-\psi_{3} \omega_{r}(\sin 3 \theta-j \cos 3 \theta)
\end{array}\right.
$$

where $\psi_{1}, \psi_{9}$ and $\psi_{3}$ are respectively the first, the ninth and the third harmonic of the flux linkage of the permanent magnets, $\omega_{r}$ is the electrical angular velocity and $\theta$ the electrical rotor position.

To perform an accurate vector control, the rotor position and speed informations are required to compute the Park transformation in the rotor reference frame. In this context, it can be seen (4) that the back-EMF signal contains these two informations. For that, an observer based on Sliding Mode will be designed, in order to estimate with high accuracy the backEMF signals necessary to extract the rotor position and speed informations.

\section{Sliding Mode Observer design for the sensorless control}

The Sliding Mode Observer (SMO) can be designed in the stationary reference frame. $(\alpha-\beta)$. Measured currents and references of voltage are used as input of the algorithm [6]. The estimation process by the SMO through each fictitious machine can be described in Fig. 2.

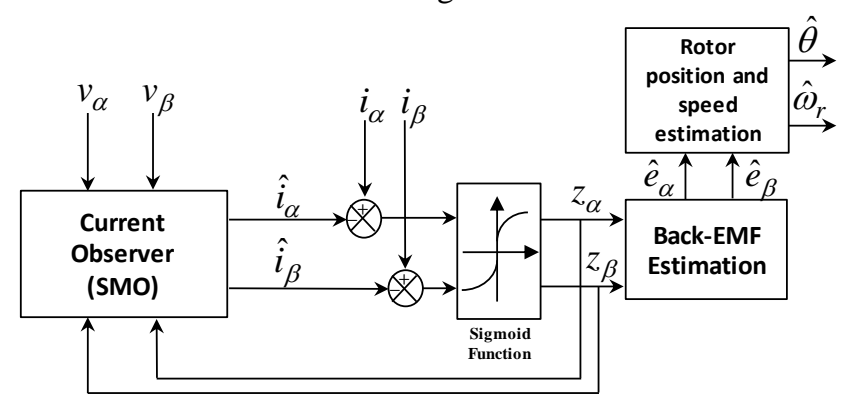

Fig. 2 Block diagram of the SMO for the sensorless control

Where $\left(v_{\alpha}, v_{\beta}\right)$ and $\left(i_{\alpha}, i_{\beta}\right)$ represent the voltages and currents in stationary reference frame $(\alpha-\beta) .\left(\hat{i}_{\alpha}, \hat{i}_{\beta}\right)$ and $\left(\hat{e}_{\alpha}, \hat{e}_{\beta}\right)$ represent respectively the estimated currents and back-EMF. The rotor position $\hat{\theta}$ and speed $\hat{\omega}_{r}$ are extracted from the estimated back-EMF $\left(\hat{e}_{\alpha}, \hat{e}_{\beta}\right)$ [6]-[7]. The sigmoid function is a continuous function used to reduce the chettering phenomenon in the SMO [6].

The estimated currents by the SMO of each fictitious machine can be expressed as [6]:

$$
\left\{\begin{array}{l}
L_{p}\left(\frac{d \overrightarrow{\hat{i}}_{\alpha \beta 1}}{d t}\right)=-R \overrightarrow{\hat{i}}_{\alpha \beta 1}+\vec{v}_{\alpha \beta 1}-k_{1} F\left(\overrightarrow{\hat{i}}_{\alpha \beta 1}-\vec{i}_{\alpha \beta 1}\right) \\
L_{s}\left(\frac{d \overrightarrow{\hat{i}}_{\alpha \beta 9}}{d t}\right)=-R \overrightarrow{\hat{i}}_{\alpha \beta 9}+\vec{v}_{\alpha \beta 9}-k_{2} F\left(\overrightarrow{\hat{i}}_{\alpha \beta 9}-\vec{i}_{\alpha \beta 9}\right) \\
L_{t}\left(\frac{d \overrightarrow{\hat{i}}_{\alpha \beta 3}}{d t}\right)=-R \overrightarrow{\hat{i}}_{\alpha \beta 3}+\vec{v}_{\alpha \beta 3}-k_{3} F\left(\overrightarrow{\hat{i}}_{\alpha \beta 3}-\vec{i}_{\alpha \beta 3}\right)
\end{array}\right.
$$

$F(x)$ is the sigmoid function [6]. We assume that:

$$
\begin{aligned}
& \left\{\begin{array}{l}
z_{\alpha 1}=k_{1} F\left(\hat{i}_{\alpha 1}-i_{\alpha 1}\right) \\
z_{\beta 1}=k_{1} F\left(\hat{i}_{\beta 1}-i_{\beta 1}\right)
\end{array}\right. \\
& \left\{\begin{array}{l}
z_{\alpha 9}=k_{2} F\left(\hat{i}_{\alpha 9}-i_{\alpha 9}\right) \\
z_{\beta 9}=k_{2} F\left(\hat{i}_{\beta 9}-i_{\beta 9}\right)
\end{array}\right. \\
& \left\{\begin{array}{l}
z_{\alpha 3}=k_{3} F\left(\hat{i}_{\alpha 3}-i_{\alpha 3}\right) \\
z_{\beta 3}=k_{3} F\left(\hat{i}_{\beta 3}-i_{\beta 3}\right)
\end{array}\right.
\end{aligned}
$$

$\left(k_{1}, k_{2}, k_{3}\right)$ represent the current observer gains. 
The back-EMF observer of each fictitious machine is built as [6]-[7]:

$$
\left\{\begin{array}{l}
\frac{d \hat{e}_{\alpha 1}}{d t}=-\hat{\omega}_{r} \hat{e}_{\beta 1}-l_{1}\left(\hat{e}_{\alpha 1}-z_{\alpha 1}\right) \\
\frac{d \hat{e}_{\beta 1}}{d t}=\hat{\omega}_{r} \hat{e}_{\alpha 1}-l_{1}\left(\hat{e}_{\beta 1}-z_{\beta 1}\right) \\
\frac{d \hat{e}_{\alpha 9}}{d t}=-9 \hat{\omega}_{r} \hat{e}_{\beta 9}-l_{2}\left(\hat{e}_{\alpha 9}-z_{\alpha 9}\right) \\
\frac{d \hat{e}_{\beta 9}}{d t}=9 \hat{\omega}_{r} \hat{e}_{\alpha 9}-l_{2}\left(\hat{e}_{\beta 9}-z_{\beta 9}\right) \\
\frac{d \hat{e}_{\alpha 3}}{d t}=-3 \hat{\omega}_{r} \hat{e}_{\beta 3}-l_{3}\left(\hat{e}_{\alpha 3}-z_{\alpha 3}\right) \\
\frac{d \hat{e}_{\beta 3}}{d t}=3 \hat{\omega}_{r} \hat{e}_{\alpha 3}-l_{3}\left(\hat{e}_{\beta 3}-z_{\beta 3}\right)
\end{array}\right.
$$

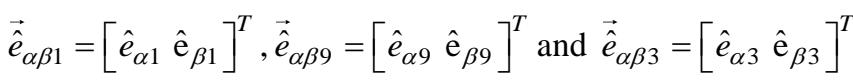
represent the estimated back-EMF in the frame $(\alpha-\beta)$ of each fictitious machine. $\left(l_{1}, l_{2}, l_{3}\right)$ represent the observer gains. The appropriate gains $\left(k_{1}, k_{2}, k_{3}\right)$ and $\left(l_{1}, l_{2}, l_{3}\right)$, are chosen in order to verify the stability of the SMO [6]-[7].

As aforementioned in section 1, two sensorless control strategies will be compared. From the back-EMF estimation (9), we can define the first strategy using only the estimated back-EMF signals of MM ( $1^{\text {st }}$ harmonic). And the second strategy, which is based on all estimated back-EMF signals $\left(1^{\text {st }}, 9^{\text {th }}\right.$ and $3^{\text {rd }}$ harmonics $)$.

3.1. Sensorless control of seven-phase PMSM using only the main fictitious machine (MM)

This sensorless control strategy uses only the main fictitious machine for SMO algorithm. The rotor position $\hat{\theta}$ is estimated from the MM, and then will be multiplied by 9 and 3 to compute respectively the $9 \hat{\theta}$ and $3 \hat{\theta}$. These angles are necessary for the control of the SM ( $9^{\text {th }}$ harmonic) and the TM ( $3^{\text {rd }}$ harmonic). This strategy, described in Fig. 4, is named as S1.

Based on the relationship between the back-EMF and the rotor position as shown in (4), the estimated values of the rotor position and speed can be expressed as:

$$
\begin{gathered}
\hat{\omega}_{r}=\frac{\sqrt{\hat{e}_{\alpha 1}^{2}+\hat{e}_{\beta 1}^{2}}}{\psi_{1}} \\
\hat{\theta}=-\arctan \left(\frac{\hat{e}_{\alpha 1}}{\hat{e}_{\beta 1}}\right)
\end{gathered}
$$

From (11) and the Fig. 3, the $9 \hat{\theta}$ and $3 \hat{\theta}$ can be expressed as:

$$
\begin{gathered}
9 \hat{\theta}=9\left(\theta-\theta_{\text {err }}\right) \Rightarrow 9 \hat{\theta}=9 \theta-9 \theta_{\text {err }} \\
3 \hat{\theta}=3\left(\theta-\theta_{\text {err }}\right) \Rightarrow 3 \hat{\theta}=3 \theta-3 \theta_{\text {err }}
\end{gathered}
$$

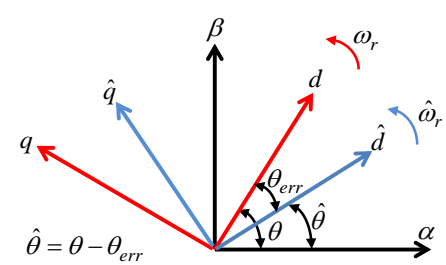

Fig.3 Relationship between the actual $(d-q)$ and estimated

$$
(\hat{d}-\hat{q}) \text { rotor frame }
$$

It can be seen from (12) and (13) that multiplying $\hat{\theta}$ by 9 and 3 to construct respectively the $9 \hat{\theta}$ and $3 \hat{\theta}$, increases significaltly the error estimation. The estimated angle, required to control SM, will contain an error 9 times bigger than $\theta_{\text {err }}$ (resulting from the estimation process of $\hat{\theta}$ by the MM signals). The error estimation contained in $3 \hat{\theta}$, required to control TM, will be 3 times bigger than $\theta_{\text {err }}$. Thus, the currents regulation of the SM and TM will be affected by the error estimation value resulted during the operation to find the rotor position. It can be noticed that such operation leads to imprecise and unefficient sensorless control, especially when the $\theta_{\text {err }}$ is important.

3.2. Sensorless control of seven-phase PMSM using all fictitious machines

The proposed sensorless control strategy is described in Fig. 4 as: S2. The voltages and currents signals of all fictitious machines are used as inputs of the SMO algorithm. This is in order to estimate separately $\hat{\theta}$ from the MM signlas, the $9 \hat{\theta}$ from the SM signals and the $3 \hat{\theta}$ from the TM signals. Unlike the strategy aforementioned (S1), the $9 \hat{\theta}$ and $3 \hat{\theta}$ are estimated separately and do not depend of the $\hat{\theta}$ (estimated from the MM signals).

Based on (4), the rotor position and speed required to control each fictitious machine can be expressed as:

$$
\begin{gathered}
\hat{\omega}_{r}=\frac{\sqrt{\hat{e}_{\alpha 1}^{2}+\hat{e}_{\beta 1}^{2}}}{\psi_{1}} \\
\hat{\theta}=-\arctan \left(\frac{\hat{e}_{\alpha 1}}{\hat{e}_{\beta 1}}\right) \\
9 \hat{\theta}=-\arctan \left(\frac{\hat{e}_{\alpha 9}}{\hat{e}_{\beta 9}}\right) \\
3 \hat{\theta}=-\arctan \left(\frac{\hat{e}_{\alpha 3}}{\hat{e}_{\beta 3}}\right)
\end{gathered}
$$

In the following section, these two sensorless control strategies will be tested on three differents seven-phase PMSMs. Each sensorless control strategy will be compared to the behaviour of the machine using an encoder (to provide the rotor position) for the control. This is in order to highlight the efficiency and robustess in terms of torque ripple and torque response of each strategy. 


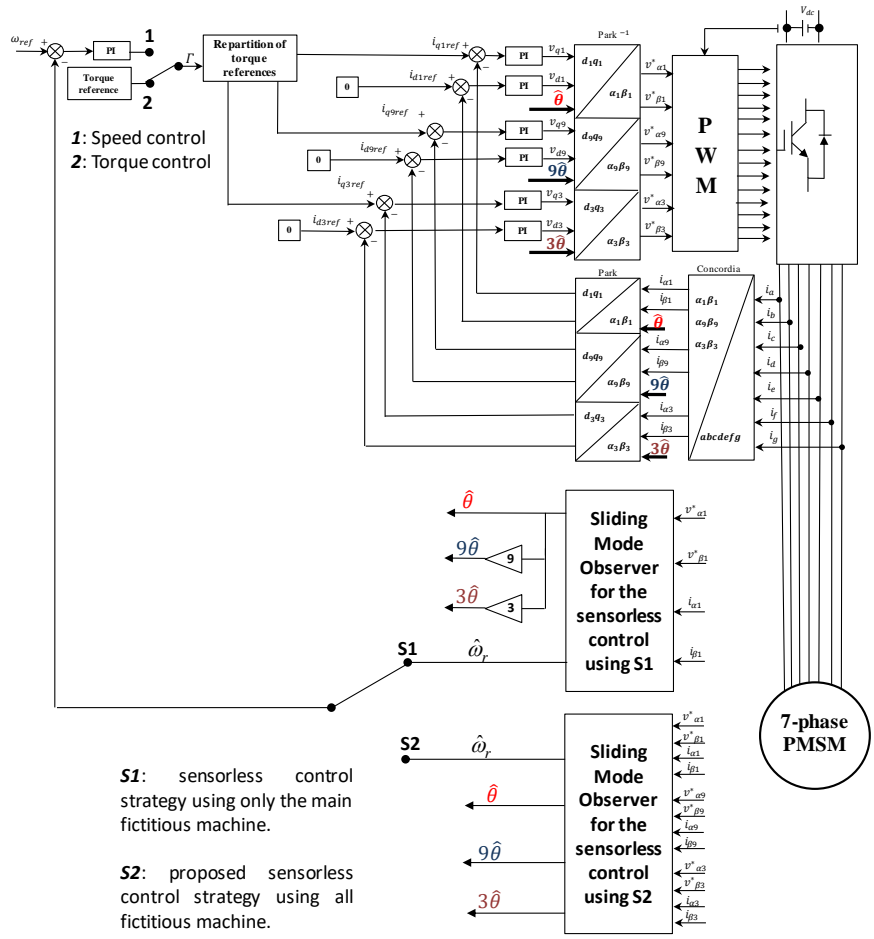

Fig. 4 Block diagram of the two sensorless control strategies for the non-sinusoidal seven-phase PMSM

Table 1 Seven-phase PMSMs characteristics

\begin{tabular}{|c|c|c|c|}
\hline Parameter Machine & M1 & M2 & M3 \\
\hline Stator Resistance R $[\Omega]$ & 1.4 & 1.4 & 0.2668 \\
\hline Phase inductance $\mathrm{L}[\mathrm{mH}]$ & 14.7 & 14.7 & 3 \\
\hline Number of pole pairs $p$ & 3 & 3 & 6 \\
\hline $\begin{array}{l}\text { Speed-normalized } \\
\text { amplitude of } 1^{\text {st }} \text { harmonic } \\
\text { back-EMF [V/rad/s] }\end{array}$ & 2.38 & 1.2650 & 0.3877 \\
\hline $\begin{array}{l}\text { Speed-normalized } \\
\text { amplitude of } 9^{\text {th }} \text { harmonic } \\
\text { back-EMF }[\mathrm{V} / \mathrm{rad} / \mathrm{s}]\end{array}$ & 0 & 0.1569 & 0 \\
\hline $\begin{array}{l}\text { Speed-normalized } \\
\text { amplitude of } 3^{\text {rd }} \text { harmonic } \\
\text { back-EMF }[\mathrm{V} / \mathrm{rad} / \mathrm{s}]\end{array}$ & 0.4760 & 0.4073 & 0.4696 \\
\hline DC bus voltage [V] & 200 & 200 & 100 \\
\hline
\end{tabular}

Table 2 Sliding mode observer parameters

\begin{tabular}{|c|l|c|l|l|c|l|}
\hline Machine Gains & $k_{1}$ & $k_{2}$ & $k_{3}$ & $l_{1}$ & $l_{2}$ & $l_{3}$ \\
\hline M1 & 200 & 0 & 400 & 300 & 0 & 2500 \\
\hline M2 & 200 & 400 & 400 & 300 & 1300 & 2500 \\
\hline M3 & 200 & 0 & 1000 & 500 & 0 & 800 \\
\hline
\end{tabular}

\section{Simulation results}

We aim by simulations is to verify the effectiveness of the proposed sensorless control strategy (S2) compared to the classical sensorless control strategy (S1), described in Fig. 4. These two sensorless control strategies of the seven-phase PMSM have been implemented in the MATLAB/Simulink. The PWM switching frequency is $10 \mathrm{kHz}$. We consider a torque control (Fig. 4) with the torque reference equal to $15 \mathrm{Nm}$ for all three seven-phase PMSMs, and the $i_{d}=0$ control strategy is carried out. The rotor speed is not required for the torque control, but it is still estimated to verify the feasibility of proposed SMO. It can be noticed that the low and zero speed region. is not considered in this study. In the sensorless control simulations, the SMO parameters are provided in Table 2.

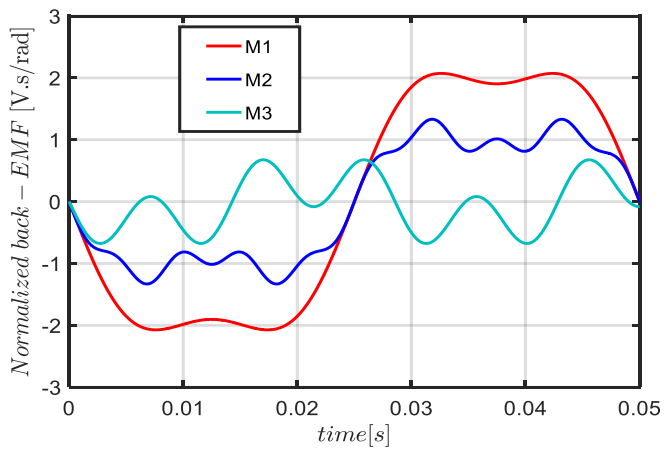

Fig. 5 : (a) normalized back-EMF of one phase of each seven-phase PMSM

\subsection{Seven-phase PMSM (M1)}

The characteristics of the seven-phase PMSM (M1) are provided in the table 1 . It presents a quasi-trapezoidal backEMF as shown in Fig. 5 [8]. We consider in the back-EMF signal only two harmonics ( $1^{\text {st }}$ and $3^{\text {rd }}$ harmonic), and the $3^{\text {rd }}$ harmonic presents $20 \%$ of the fundamental of back-EMF.

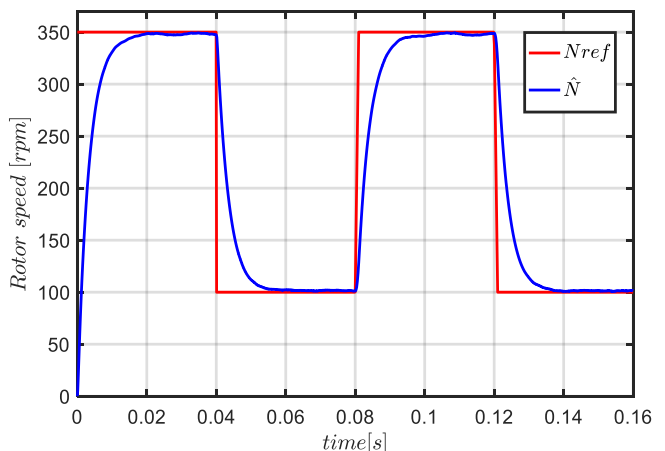

(a)

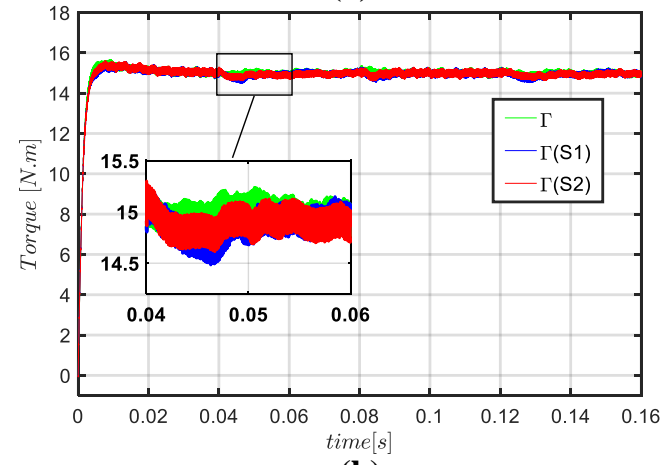

(b) 


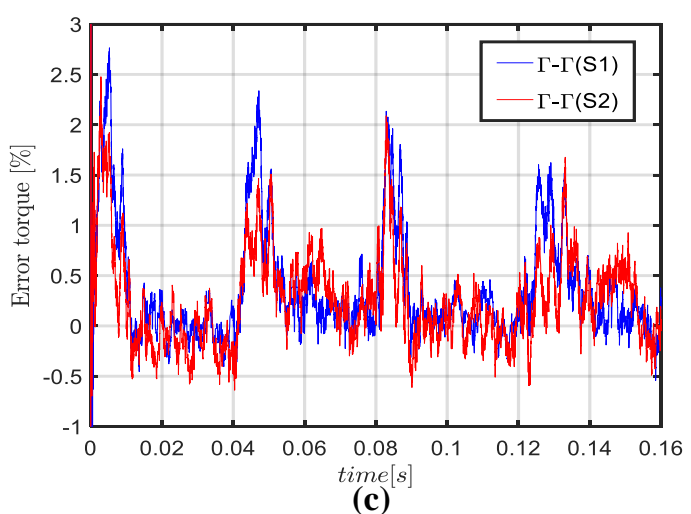

Fig. 6 : (a) Reference and estimated rotor speed, (b) measured torque (using an encoder, using strategy $\mathbf{S 1}$ and using strategy S2), (c) error between the measured torque (using an encoder) and the measured torque (using strategy $\mathbf{S 1}$ or $\mathbf{S 2}$ )

It can be seen from the Fig. 6 (a) that the SMO ensure a precise estimation of the rotor speed. The Fig. 6 (b) shows clearly that the difference between the measured torque using an encoder (to provide the rotor position) and the measured torque using sensorless control (whether this is strategy $\mathbf{S 1}$ or S2) is not significant in the transient states and steady states. Then in Fig.6 (c), the error between the measured torque using an encoder and the one using sensorless control strategy (S1 or S2) is less than $2.5 \%$

\subsection{Seven-phase PMSM with non-sinusoidal back-EMF} (M2)

The seven-phase PMSM (M2) has the same stator of machine (M1), but not the same rotor. The characteristics of the machine M2 are provided in the table 1. It presents a nonsinusoidal back-EMF as shown in Fig. 5 [9]. The back-EMF signal contains three harmonics $\left(1^{\text {st }}, 9^{\text {th }}\right.$ and $3^{\text {rd }}$ harmonic). The $9^{\text {th }}$ harmonic presents $12 \%$ of the fundamental, and the $3^{\text {rd }}$ harmonic is $32 \%$ of the fundamental of back-EMF.

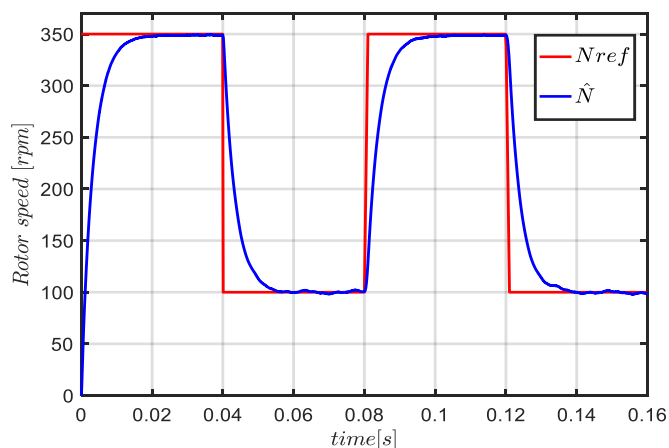

(a)

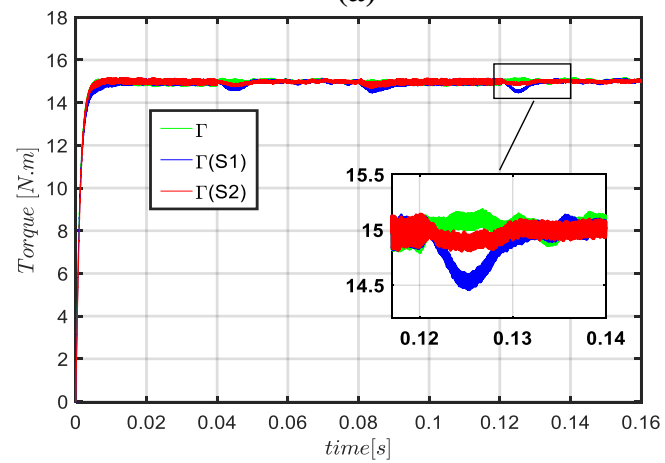

(b)

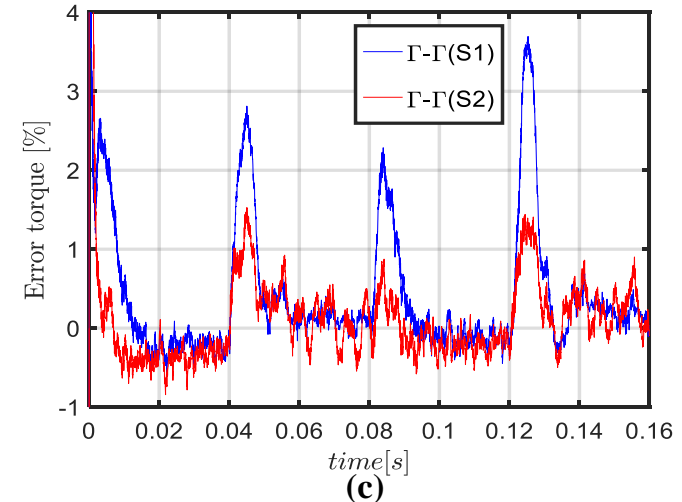

Fig. 7 :(a) Reference and estimated rotor speed, (b) measured torque (using an encoder, using strategy $\mathbf{S 1}$ and using strategy S2), (c) error between the measured torque (using an encoder) and the measured torque (using strategy $\mathbf{S 1}$ or S2)

Unlike the simulation results of the seven-phase PMSM (M1), it can be seen in Fig. 7 (b) that the strategy $\mathbf{S 2}$ ensure a precise sensorless control in terms of torque ripple compared to the strategy S1, specially in transient states Then, it can be seen in Fig. 7 (c) that in transient state the measured torque using strategy S1 present a torque ripple which double the one obtained in the strategy S2. However, the two strategies present the same level of accuracy and efficiency in the steady state.

As the back-EMF of the machine (M2) contains the $9^{\text {th }}$ and $3^{\text {rd }}$ harmonics, and based on (12) and (13), it can be verified that the effect of multiplying $\hat{\theta}$ by 9 and 3 increase significantly the $\theta_{\text {err }}$, and lead to a torque ripple in transient state.

\subsection{Seven-phase bi-harmonic PMSM (M3)}

The seven-phase PMSM (M3) is a bi-harmonic machine, and it is during the manufacture. The characteristics of the biharmonic machine (M3) are provided in the table 1. The backEMF signal is shown in Fig. 5 [10], and contains two harmonics ( $1^{\text {st }}$ and $3^{\text {rd }}$ harmonic). The $3^{\text {rd }}$ harmonic is $121 \%$ of the fundamental of back-EMF.

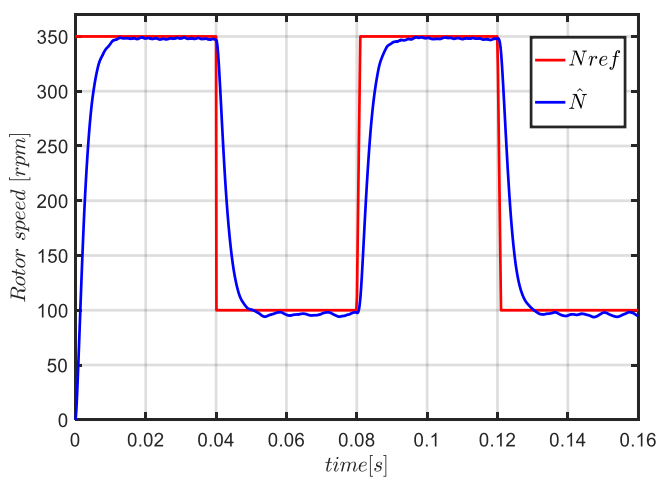

(a)

The most important part of torque of the bi-harmonic machine (M3) is procuded by the $3^{\text {rd }}$ harmonic of the back-EMF (associated to TM). Therefore, the estimated rotor position $3 \hat{\theta}$ required to control the TM of the real seven-phase PMSM should be precise in order to ensure an accurate currents regulation leading to an efficient vector control. 


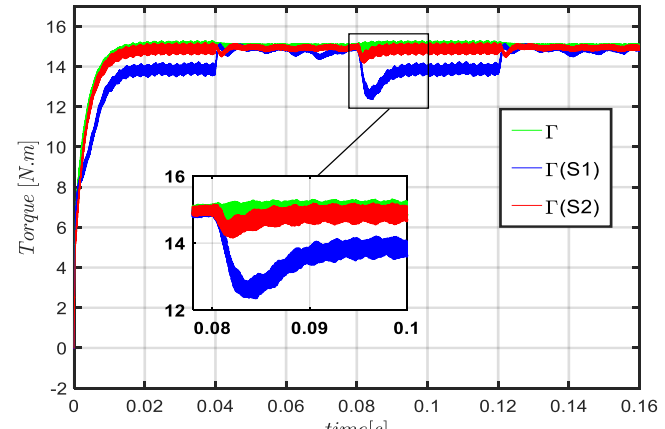

(b)

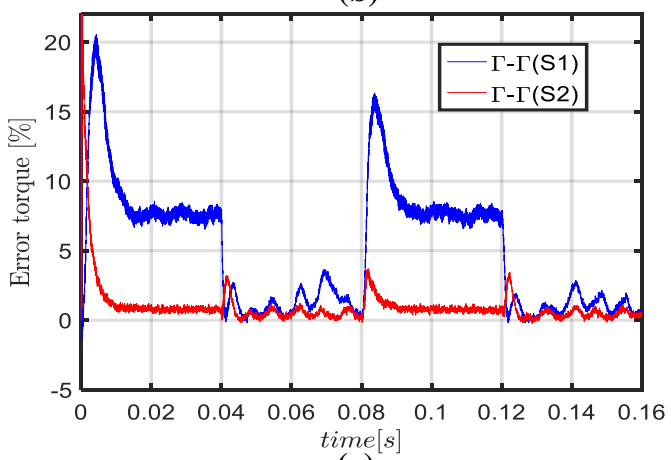

(c)

Fig. 8 : (a) Reference and estimated rotor speed, (b) measured torque (using an encoder, using strategy $\mathbf{S 1}$ and using strategy S2), (c) error between the measured torque (using anencoder) and the measured torque (using strategy $\mathbf{S 1}$ or $\mathbf{S 2}$ )

As the sensorless control strategy $\mathbf{S 1}$ multiplies the $\hat{\theta}$ by 3 to compute the $3 \hat{\theta}$, the resulting error position $3 \theta_{\text {err }}$ incrases directly (three times bigger than $\theta_{\text {err }}$ ). Thus, it can be seen in Fig. 8 (b) and (c) that the measured torque using strategy $\mathbf{S 1}$ is impacted in both transient state and steady state. However, in the same aformentionned figures, it can be noticed that the measured torque using the strategy $\mathbf{S 2}$ presents a low torque ripple and good torque response in the transient and steady states. The error between the measured torque using an encoder and the one using the sensorless control strategy $\mathbf{S 2}$ is less than $4 \%$.

\section{Conclusion}

This paper presents two sensorless control strategies based on sliding mode observer for seven-phase PMSM. Based on the simulation results, it can be concluded that for multiphase machines producing mainly the torque by only the fundamental back-EMF and currents (MM), the two sensorless control strategies (S1 and S2) present the same level of robustness against the speed variations and torque ripple. However, for the sensorless control of multiphase machines which produce the torque through not only the MM, but also the MM, SM and TM, the proposed strategy S2 (using all hamonics contained in the back-EMF) presents a good control performance in terms of robustness and torque ripple compared to the strategy S1. Furthermore, the proposed sensorless control strategy S2 doesn't ask additional hardwares to be implemented in the real time since the algorithm is quite similar as $\mathbf{S 1}$, but the number of observer is multiplied by three.

\section{Acknowledgment}

This work has been achieved within the framework of CE2I project. CE2I is co-financed by European Union with the financial support of European Regional Development Fund (ERDF), French State and the French Region of Hauts-deFrance.

\section{References}

[1] Y. Burkhardt, A. Spagnolo, P. Lucas, M. Zavesky, and P. Brockerhoff, "Design and analysis of a highly integrated 9-phase drivetrain for EV applications," in 2014 International Conference on Electrical Machines (ICEM), 2014, pp. 450-456.

[2] P. Vas, Sensorless Vector and Direct Torque Control Oxford University Press, 1998, pp. 1-729.

[3] Y. Mei, K. Sun, and Y. Shi, "A 2-D fuzzy logic based MRAS scheme for sensorless control of interior permanent magnet synchronous motor drives with cyclic fluctuating loads," Chinese Journal of Electrical Engineering, vol. 1, no. 1, pp. 85-91, 2015. T. Michalski, C. Lopez, A. Garcia, and L. Romeral, "Sensorless control of five phase PMSM based on extended Kalman filter," in IECON 2016 - 42nd Annual Conference of the IEEE Industrial Electronics Society, 2016, pp. 2904-2909.

X. Zhang, G. Tian, Y. Huang, and Z. Lu, "A Comparative Study of PMSM Sensorless Control Algorithms: Model Based vs Luenberger Observer," in 2016 IEEE Vehicle Power and Propulsion Conference (VPPC), 2016, pp. 1-6.

[6] J. Yang, M. Dou, and D. Zhao, "Iterative sliding mode observer for sensorless control of five-phase permanent magnet synchronous motor," Bulletin of the Polish Academy of Sciences Technical Sciences, vol. 65, no. 6, pp. 845-857, 2017.

[7] L. Zhang, Y. Fan, C. Li, A. Nied, and M. Cheng, "Fault-Tolerant Sensorless Control of a Five-Phase FTFSCW-IPM Motor Based on a Wide-Speed Strong-Robustness Sliding Mode Observer," IEEE Transactions on Energy Conversion, vol. 33, no. 1, pp. 87-95, 2018.

[8] F. Locment, E. Semail, and X. Kestelyn, "Vectorial Approach-Based Control of a Seven-Phase Axial Flux Machine Designed for Fault Operation," IEEE Transactions on Industrial Electronics, vol. 55, no. 10, pp. 3682-3691, 2008.

[9] D. T. Vu, N. K. Nguyen, E. Semail, and T. J. d. S. Moraes, "Control strategies for non-sinusoidal multiphase PMSM drives in faulty modes under constraints on copper losses and peak phase voltage," IET Electric Power Applications, vol. 13, no. 11, pp. 1743-1752, 2019.

[10] HAO Zhang et al., "Torque Optimization of a SevenPhase Bi-harmonic PMSM in Healthy and Degraded Mode," presented at the ICEMS 2019, The 22nd IEEE International Conference on Electrical Machines and Systems, Harbin, China, 08/2019, 